\title{
VARIATIONS IN ENVIRONMENTAL TRITIUM DOSE ESTIMATES DUE TO METEOROLOGICAL DATA AVERAGING AND UNCERTAINTIES IN PATHWAY MODEL PARAMETERS
}

\author{
A. L. KOCK and D. M. HAMBY* \\ Department of Environmental and Industrial Health, School of Public Health, University of \\ Michigan, Ann Arbor, MI 48109-2029, U.S.A. \\ E-mail:dmhamby@umich.edu
}

(Received 29 November, 1996; accepted 15 May, 1997)

\begin{abstract}
The large amounts of tritium produced at the Savannah River Site (SRS) coupled with the current dose reconstruction study at the facility emphasize the importance of ensuring accurate and efficient prediction of tritium doses to the public. Presently, dose estimates to the general population in the site vicinity are calculated annually using a five year meteorological database. Determining whether detailed monthly dose estimates are necessary or whether annual averaged data is sufficient offers the potential for more efficient dose prediction. In this study, off site collective committed doses and maximum individual doses due to atmospheric tritium releases were calculated according to the methods outlined in the U.S. Nuclear Regulatory Commission's Regulatory Guide 1.109 and compared using monthly versus five-year meteorological data and source terms. Site-specific variables not currently utilized at SRS for annual dose estimates also have been included. In addition, the range of predicted doses, based on the distribution in model parameters given in the literature, were estimated. Finally, a sensitivity analysis was performed in order to determine the influence of model inputs on dose estimates. Results corroborate previous studies by indicating that the primary contributor to infant tritium dose is the ingestion of milk, while for all other age groups, the most important pathway is the ingestion of vegetation. These relative pathway contributions remain constant throughout the year for infants; for children, teenagers, and adults, however, inhalation and absorption of tritium through the skin increases in relative importance in the months of June to September. It was found that the model utilized was most sensitive to dose factors, the ratio of the specific activity of tritium oxide in vegetation to the specific activity of atmospheric tritium oxide, and breathing rates. Most importantly, it was found that over a five-year period, the use of averaged meteorological data results in total individual doses that are only 2 to $6 \%$ higher than doses determined monthly, depending on the pathway of interest.
\end{abstract}

Key words: atmospheric transport, dose reconstruction, Gaussian dispersion, Savannah River Site

\section{Introduction}

The Savannah River Site (SRS) was constructed in 1952 for the purpose of producing weapons-grade plutonium and tritium. Operation of the site has resulted in the release of low level radioactive materials to the atmosphere and environmental waters. Dose assessments to off site populations have indicated that tritium is the most significant contributor to environmental dose. Furthermore, atmospheric tritium release levels have consistently exceeded liquid tritium release levels (Murphy et al., 1993). Contrary to the results of reactor probabilistic studies, routine operation contributes an appreciable portion $(\sim 50 \%)$ of the risk posed by nonreactor

* Corresponding author. 
tritium facilities, indicating that accurate dose assessments due to routine site operations are imperative (O'Kula et al., 1992). In addition, it is possible that tritium releases to the environment may increase in the future due to development of fusion technology for electrical power generation (Opkada and Momoshima, 1993). For these reasons, it is important to predict tritium doses to the public accurately and efficiently.

Several uncertainties exist in the parameters used to model off site atmospheric tritium doses to populations in the vicinity of the Savannah River Site. Although a range of values is possible for each input parameter in a model, in many instances parameters are represented by a single quantity (or default value in the absence of site-specific data) chosen through subjective judgment. In addition, some model parameters are not modified to site-specific or seasonal values at the Savannah River Site. For example, although site methodology accounts for an area-specific absolute humidity value, seasonal humidity variations are not incorporated into the site model; however, it has been demonstrated that calculated air concentrations vary widely depending on the value of relative humidity utilized (Murphy, 1984). At low environmental doses, the implications of model uncertainties are not expected to be significant. However, economic and political costs of parameter uncertainties may be profound if conservative models erroneously predict compliance or violation of the regulatory limits (WSRC, 1991). Given the importance of off site tritium doses and emphasis on compliance with DOE regulations, quantifying uncertainties and determining their impact on dose estimates will be a significant achievement.

Calculation of age-dependent environmental tritium doses would be of value in site environmental dose assessments. Although age dependent consumption is utilized in present site methodology, the use of current age-dependent dose factors (ICRP 89; ICRP 93) is desirable. Previous studies have indicated that age dependence in relation to dose may be particularly significant in the case of tritium (Etnier and Till, 1979).

Determining whether detailed monthly dose estimates are necessary or whether annual averaged data is sufficient offers the potential for more efficient future dose reconstruction studies. Dose estimates are presently calculated annually using five-year meteorological databases (WSRC, 1995; USNRC, 1978). The degree to which monthly release and meteorological data are appropriate for population dose estimates and reconstructions is not known. Monthly estimates may provide more meaningful doses, or five-year averaged data may prove to be adequate for routine monitoring and dose reconstruction purposes.

The radiation protection problem introduced by tritium is accentuated in the Savannah River Site environment; tritium accounts for the majority of off site doses at the Savannah River Site. For example, in 1994 approximately 88\% of the site perimeter doses from atmospheric releases were attributed to tritium (WSRC, 1994). The mobility of tritium coupled with the magnitude of tritium released at the site warrants research efforts providing more efficient and meaningful dose assessments in regard to site operations. 
Presently, the SRS Environmental Dosimetry Group calculates off site tritium air concentrations due to atmospheric releases using the Gaussian atmospheric dispersion model

$$
\begin{array}{rll}
\chi=\frac{Q}{2 \pi \sigma_{y} \sigma_{z} \bar{u}} & \exp \left(-\frac{y^{2}}{2 \sigma_{y}^{2}}\right) \exp \left[\left(-\frac{(z-h)^{2}}{2 \sigma_{z}^{2}}\right)+\left(-\frac{(z+h)^{2}}{2 \sigma_{z}^{2}}\right)\right] \\
\text { where } Q & =\text { release rate } & (\mathrm{Ci} / \mathrm{s}) ; \\
h & =\text { stack height } & (\mathrm{m}) ; \\
y & =\text { lateral distance from center of plume } & (\mathrm{m}) ; \\
z & =\text { vertical distance from ground } & (\mathrm{m}) ; \\
\sigma_{y} & =\text { lateral diffusion coefficient } & (\mathrm{m}) ; \\
\sigma_{z} & =\text { vertical diffusion coefficient } & (\mathrm{m}) ; \\
\bar{u} & =\text { average wind speed } & (\mathrm{m} / \mathrm{s}) .
\end{array}
$$

Average annual air concentrations in sixteen sectors surrounding the site are calculated using the sector-averaged Gaussian equation which averages concentrations over the sector width and accounts for the frequency of occurrence of specific meteorological conditions

$$
\bar{\chi}_{\text {sector }}=\sum_{i j k} \frac{6.301 Q}{\pi x \sigma_{z} \bar{u}_{i j k}} \exp \left(-\frac{h^{2}}{q \sigma_{z}^{2}}\right) \cdot f_{i j k}
$$

where $f_{i j k}=$ frequency of occurrence of windspeed $i$, atmospheric stability $j$, and wind direction $k$. These frequencies are determined through the use of meteorological measurements recorded over a five-year period at the $\mathrm{H}$-area tower, near the center of the SRS.

Dispersion of atmospheric tritium released at the site is modeled by incorporating the diffusion variables $\sigma_{y}$ and $\sigma_{z}$ in the above Gaussian equation. Atmospheric stability in $\mathrm{H}$ area is determined through the standard deviation of the horizontal and vertical wind directions measured with a bi-vane on the meteorological tower.

Concentrations of tritium oxide in foodstuffs, $C_{v}$, were estimated using a specific-activity model (Anspaugh et al., 1973; U.S. NRC, 1977),

$$
C_{v}=C_{a} \frac{f_{w} R}{H},
$$

where $C_{a}$ is the tritium concentration in air, $f_{w}$ is the fraction of vegetation that is water, $R$ is the activity ratio of tritium oxide in vegetation to that in atmospheric moisture (Hamby and Bauer, 1994), and $H$ is the absolute humidity. Deposition, therefore, is not considered directly, but is modeled implicitly.

The annual 50-mile collective committed dose and maximum individual dose at the site perimeter are calculated at the Savannah River Site for inhalation and 
ingestion of milk, meat, and vegetables using methods described in the U.S. Nuclear Regulatory Commission's Regulatory Guide 1.109 (1977). Currently at SRS, adult internal dose factors for inhalation and ingestion are utilized for dose calculations (DOE/EH-0071).

The site methodology also utilizes several site-specific parameters in modeling atmospheric releases as opposed to incorporating NRC default values (Hamby, 1992). However, several parameters which may influence off site dose estimates have not been modified to reflect site-specific conditions. Seasonal consumption variation, age-dependent dose factors, seasonal variability in the absolute humidity, and inversion height at the site are not included explicitly in dose estimates. Dose prediction variations for ingestion pathways differ significantly based on consumption rates used and absolute humidity. The use of site-specific model parameters has been shown to result in a $4 \%$ decrease in population dose estimates at the Savannah River Site (Hamby, 1992).

Present dose estimations at the Site do not utilize uncertainty analysis techniques. A probability density function of dose to a maximally exposed adult, however, has been calculated based on assumed parameter distributions and an estimate of the annual atmospheric tritium concentration at the site boundary (Hamby, 1993). Such a distribution has not been estimated when considering temporal release patterns, various age groups, or population dose estimates. These considerations will be taken into account in the calculations that follow.

\section{Methods}

\subsection{Calculation of Air CONCENTRATions}

Monthly and annual concentrations of tritium in air during the years of 1987 to 1991 were calculated in the west-northwest sector at the site boundary ( 7.35 miles) and 15, 25, 35, and 45 miles from an assumed centralized release point (see Figure 1). In performing these calculations, monthly meteorological and $\mathrm{H}$-Area release data were incorporated into the annual sector-average Gaussian dispersion model.

Meteorological data for each month in the five-year period from 1987 to 1991 were characterized in terms of stability class, wind speed category, and wind direction for monthly dispersion analysis in the west-northwest sector. In addition, annual frequency data regarding wind speed category and atmospheric stability for the west-northwest sector were generated. These joint frequency distributions were utilized in calculating monthly- and annual-averaged sector air concentrations using the Gaussian sector-averaged equation.

Decay of tritium as the modeled plume disperses was assumed to be insignificant and was not considered. The $\mathrm{H}$-area stack height of $61 \mathrm{~m}$ was used in all calculations. The assumptions of no plume depletion and no resuspension considered at the site were upheld. Flat terrain was also assumed (WSRC, 1995). 


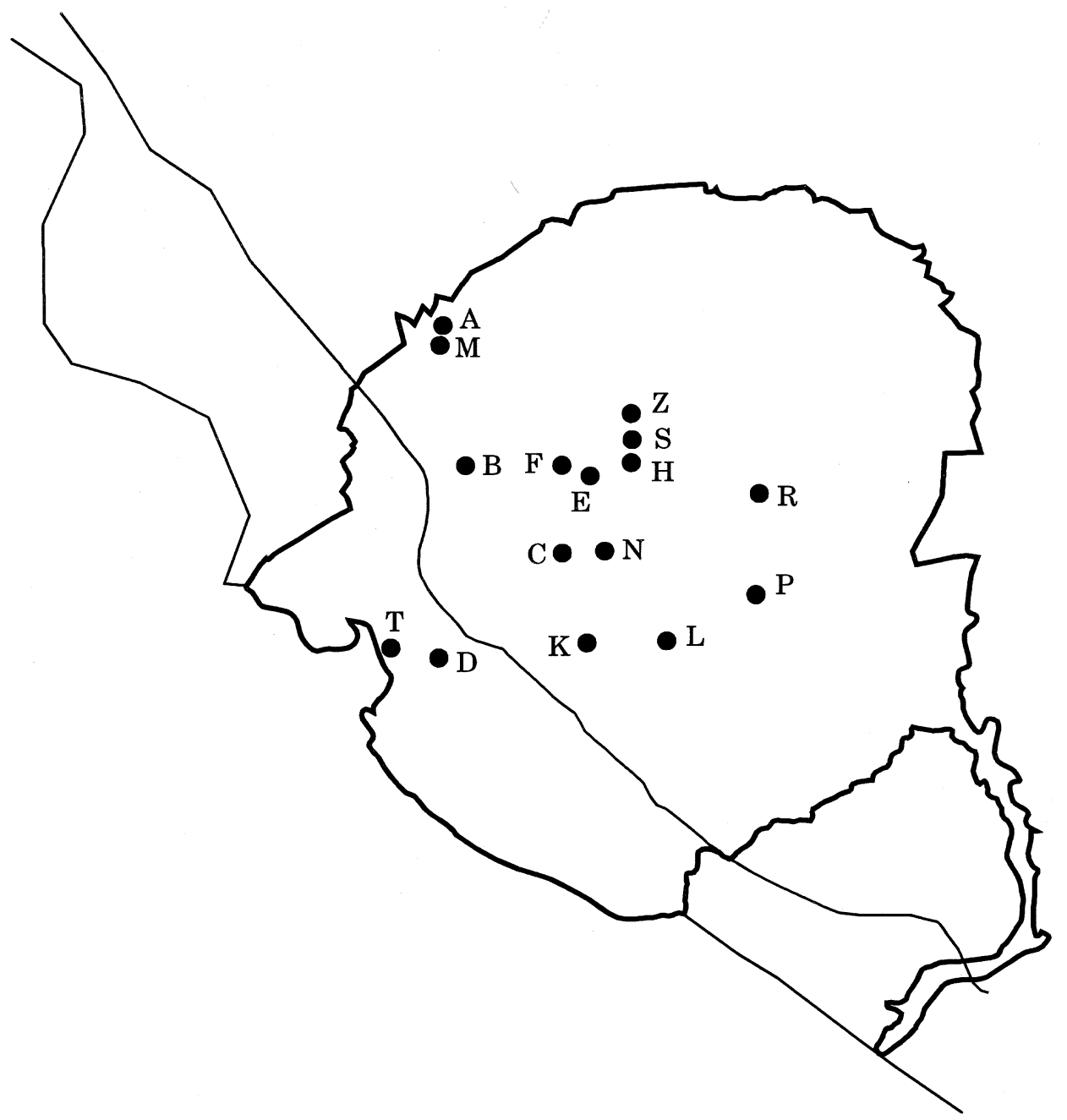

Figure 1. Savannah River Site map. Meteorological data were collected from the tower situated in $\mathrm{H}$ Area and tritium releases were assumed to occur at the site center.

The tritium release rate for each month was calculated from site release data. It is assumed that $10 \%$ of the elemental tritium released is converted to tritium oxide during transport downwind. Vertical diffusion $\left(\sigma_{z}\right)$ was estimated using the mathematical dispersion relations of Pasquill-Gifford outlined by Brodsky (1982). In addition, measured seasonal inversion height data were incorporated into monthly spreadsheets. An average inversion height of $1000 \mathrm{~m}$ was assumed for each annual calculation, as is site practice. 


\subsection{CONCENTRATION CALCULATIONS}

The concentration of tritium in leafy vegetables, beef, milk, and non-leafy vegetables, fruits, and grains were determined at the site boundary and at 15, 25, 35, and 45 miles from the release point on an annual and monthly basis using the specificactivity model described above. Site methodology was modified to include monthly humidity data; the absolute humidity in all annual calculations was assumed to be $11.4 \mathrm{~g} \mathrm{~m}^{-3}$ since this represents the mean absolute humidity at the site (Hamby and Jumper, 1990).

\subsection{Calculation of doses}

Collective committed doses within 50 miles of SRS and maximum individual doses at the site boundary were calculated using the 1987 to 1991 meteorological database. Doses due to inhalation and absorption of tritium through the skin, ingestion of beef, vegetation, and milk, were calculated based on methods outlined in NRC Regulatory Guide 1.109. Dose calculation methodology included the use of site-specific data, age dependent dose factors, and seasonal consumption rates. Age dependent inhalation and ingestion dose factors were taken from ICRP 56 (1989). Age dependent breathing rates were also utilized. Maximum and average individual seasonal consumption rates were derived from the US Department of Agriculture 1977-78 Food Consumption Survey of Southern Households (USDA, 1983).

\subsection{PARAMETER SENSITIVITY AND DOSE DISTRIBUTIONS}

Parameter characteristics cited in the literature were utilized in determining the range of doses calculated. The distribution in total dose for maximum individuals and the population as well as the percentiles for each distribution were determined using Latin Hypercube sampling. One thousand dose estimates were calculated using the Gaussian atmospheric tritium dose model; Hamby (1993) indicated that the statistics of the dose distribution are not significantly improved by increasing the number of trials above 1,000. In addition, the sensitivity of each parameter was calculated in order to determine its influence on model output, i.e., the calculated dose.

\section{Results}

\subsection{COMPARISON OF DOSES BASED ON FIVE YEAR AND MONTHLY METEOROLOGICAL DATA}

Monthly doses by pathway were summed over a year's time and compared to doses estimated by annual-averaged methods in order to determine the importance 


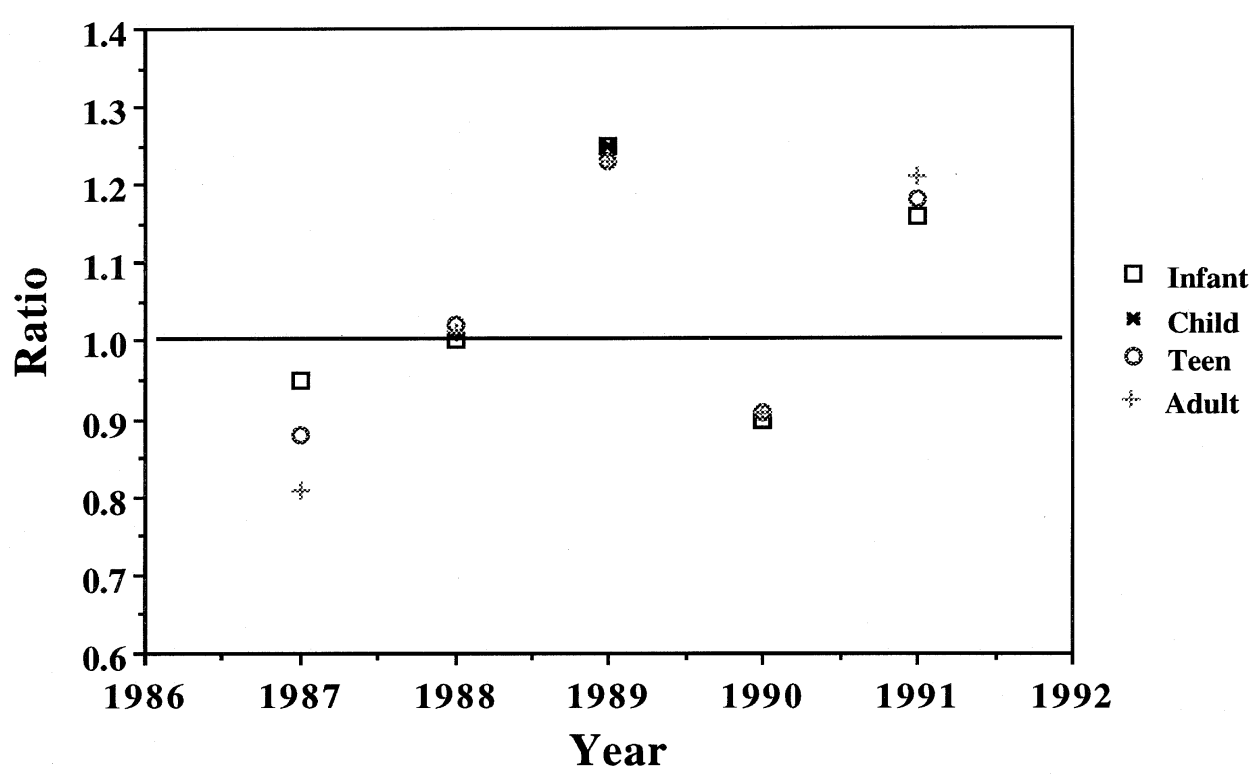

Figure 2. Ratio of annual-average to monthly-summed maximum individual dose estimates.

of monthly dose determinations. Plots of the ratio of annual averaged to summed monthly maximum individual dose for each pathway were calculated. A representative plot for total-dose estimates in the five-year period is given in Figure 2. It is evident that maximum individual dose, determined monthly, is not consistently over- or under-estimated by annual-averaged parameter values for any pathway. However, the average ratio of annual averaged to summed monthly values over five years is over-predicted in each pathway. The magnitudes of these differences are indicated in Table I, with a consistent trend for all pathways. This is expected since the degree to which averaged meteorological data represents monthly conditions is reflected in all pathways. In addition, dose estimate variation, or discrepancies, from monthly-summed versus annual-averaged input values is consistent for all age groups. This finding is an artifact of identical equations utilized in the dose calculation for each age group.

Dose discrepancies for the two averaging times were found to originate in misrepresentations of monthly meteorological data by five-year averaged frequency distributions. These discrepancies are reflected in divergent air concentrations. For example, the summed population total dose in 1990 differs from the annual averaged value by $6 \%$, while the 1991 comparison indicated a difference of $26 \%$. This difference in the ability of five-year averaged data to represent monthly doses is depicted in differences in air concentrations when comparing annual-averaged concentrations with the average of monthly concentrations; in 1990, the average difference in air concentrations was $6.6 \%$, while in 1991 this difference was $28.2 \%$. The 1990 population dose is better represented by the five-year data because 
Table I

Ratios of annual-averaged to monthly-averaged doses over five-year assessment period

\begin{tabular}{llll}
\hline & $\begin{array}{l}\text { Average } \\
\text { overestimate } \\
\text { for maximum } \\
\text { individuals }\end{array}$ & $\begin{array}{l}\text { Average } \\
\text { overestimate } \\
\text { for population }\end{array}$ & $\begin{array}{l}\text { Mean } \\
\text { overall } \\
\text { estimate }\end{array}$ \\
\hline $\begin{array}{l}\text { Tathway Dose } \\
\text { Inhalation and }\end{array}$ & $4 \%$ & $6 \%$ & $5 \%$ \\
$\quad$ skin absorption & $6 \%$ & $6 \%$ & $6 \%$ \\
Milk & $2 \%$ & $3 \%$ & $2 \%$ \\
Beef & $2 \%$ & $6 \%$ & $3 \%$ \\
Vegetation & $4 \%$ & $6 \%$ & $5 \%$ \\
\hline
\end{tabular}

Table II

Percent contributions to total dose by pathway and age group

\begin{tabular}{lcccc}
\hline & Infants & Children & Teenagers & Adults \\
\hline Milk & $54 \%$ & $26 \%$ & $18 \%$ & $10 \%$ \\
Beef & - & $2 \%$ & $3 \%$ & $5 \%$ \\
$\begin{array}{l}\text { Vegetation } \\
\begin{array}{c}\text { Inhalation and } \\
\text { absorption }\end{array}\end{array}$ & $33 \%$ & $48 \%$ & $41 \%$ & $44 \%$ \\
\hline
\end{tabular}

the meteorological conditions during this year more closely parallel conditions represented by the five-year meteorological data set; in 1990, the average percent difference in annual-averaged and monthly-averaged wind speeds was $8.9 \%$, and the percent difference in frequency estimations was $52.9 \%$. This can be contrasted with percent differences in 1991 of $10.5 \%$ and $76.1 \%$, respectively.

As expected, population dose differences in all pathways follow the trends noted for maximum individuals. This finding is due to the fact that discrepancies in doses stem from differences in air concentrations. Discrepancies in any given month are reflected in concentration calculations for maximum individuals and the population equally. However, slight differences in ratios between maximum individual and population doses (within 10\%) were noted due to averaging variations for age group and downwind distance in population calculations. Population total doses are not consistently over- or under-estimated by averaged data. However, the mean of annual averaged to monthly summed ratios over $5 \mathrm{yr}$ is greater than unity for every pathway, indicating an average over-estimate of monthly doses by fiveyear averaged meteorological data. Population and maximum individual doses are equally over-estimated in each pathway. Variations by pathway are given in Table II. 
Differences were noted in the accuracy of averaged data when predicting doses due to ingestion of foods in comparison with the inhalation pathway. For example, in 1990, annual averaged maximum individual inhalation doses differed from summed monthly doses by $6 \%$. However, the percent difference between annual averaged and summed monthly maximum individual milk doses in 1990 was $12.5 \%$. This difference may be attributed to the relative effect of air concentration on inhalation and ingestion doses. Specifically, differences in air concentrations are directly reflected in inhalation and absorption doses, while differences in ingestion doses are indirectly influenced through concentrations in foodstuffs. For example, an averaged air concentration which is higher than a monthly concentration may be negated by a monthly humidity value which is lower than the annual average humidity. In addition, the slightly less extreme over-estimates noted for the milk and beef pathways in comparison to vegetation doses may be attributed to the relatively constant consumption of milk and beef and the variability of vegetation consumption throughout the year.

\subsection{RELATIVE DOSES AMONG AGE GROUPS}

Dose hierarchies yield a pattern of total dose among age groups as follows

$$
\text { infants }>\text { children }>\text { teens }>\text { adults }
$$

This hierarchy is understood through examination of usage and dose factors for the four age groups. Although infant beef and inhalation doses are less than doses in any other age group due to lower usage factors, infant vegetation and milk doses are larger than comparative doses in other age groups. Infant milk doses are relatively high due to greater consumption of milk by infants relative to other age groups. Although infants, on average, consume less vegetation than adults (a factor of 0.43 less), the large difference in the recommended dose factor results in an increased vegetation dose. Similarly, child total doses are next highest due to their increased consumption of milk over other age groups and the large dose factor applied. Finally, although an identical dose factor is applied in the case of teenagers and adults, the increase consumption of milk by teenagers over adults results in an increased teenage total dose.

\subsection{Pathway CONTRibutions to total dose}

Relative contributions of exposure pathways to total dose for different age groups have their basis in differences in the concentrations of tritium in food items and differences in consumption rates. Representation of pathway contributions to total dose are given for 1987 below. While the data are presented for only one year, results were shown to be applicable to all years. Comparisons of model output to measured tritium concentrations can be found elsewhere (Hamby and Bauer, 1994; Simpkins and Hamby, 1997). 
One indication of the importance of a pathway exposure to total dose is the concentration of tritium in the food item of interest. For a given air concentration, the concentration of tritium in vegetation is highest among food groups. This finding is a result of the concentration of tritium oxide in vegetation being $54 \%$ of that in atmospheric water vapor (Hamby and Bauer, 1994), while for beef and milk, only approximately $1.2 \%$ of the daily tritium ingested appears in the animal per kg of muscle or liter of milk under steady state conditions. Secondly, for a given air concentration, the tritium concentration in milk is higher than in beef. The most prominent contributing factor to this finding is that dairy cattle have a greater feed consumption rate than beef cattle. Pathway contributions are evident when these considerations are taken into account.

Pathway contributions to total dose for each age group are provided in Table II. The major contributor to infant tritium ingestion dose is milk consumption. Although tritium concentrations in vegetation are higher than in milk at a given air concentration by approximately a factor of 1.9 , infants consume approximately 3.1 times more milk than vegetation. The next primary contributor to infant dose is vegetation due to the high concentrations noted in this food item relative to other foods. The major contributor to child total dose is the ingestion of vegetation; milk consumption rates by children are not significant enough to deem milk ingestion the primary contributor, although it is the pathway of secondary importance. Due to the relatively large concentration of tritium in vegetation relative to other food items and the fact that teenagers consume mostly vegetation, this pathway contributes the highest percentage to total teenage dose. Adult contributions closely parallel teenage contributions due to similar usage rates.

Pathway contributions to population dose were also examined. Inhalation and absorption of tritium through the skin is the primary contributor (87\%) to population dose. This is attributed to population demands for food items being larger than local production can supply in most cases. Further, of the food imported into the region, only a fraction is assumed to be contaminated. This may be contrasted with the assumption that all food consumed is contaminated in the calculation of maximum individual doses. Other factors contributing to this result are the large fraction of the population that are adults ( $71 \%$ ) coupled with the significance of inhalation and absorption as a mode of exposure for the adult population.

Finally, pathway contributions to total dose for the different age groups throughout the year were investigated. The age-group hierarchy for pathway contributions are consistent with those noted above. Pathway contributions for infants are constant due to the large contribution to total dose from milk ingestion coupled with constant infant milk consumption rates through the seasons. In the case of children, pathway contributions are as indicated above in all months except June, July, August, and September. In these months, inhalation and absorption is the secondary contributor, while milk ingestion becomes the tertiary contributor. The change in pathway contributions for these months is attributable to higher monthly humidity at this time of year, and a resulting lower concentration in pasture grass and veg- 
Table III

Tritium dose model parameters listed in order of sensitivity with their associated sensitivity coefficent

\begin{tabular}{ll}
\hline Variable & $\begin{array}{l}\text { Sensitivity } \\
\text { coefficient }^{\mathrm{a}}\end{array}$ \\
\hline Inhalation dose factor & 95 \\
Ingestion dose factor & 53 \\
Vegetation-to-air concentration ratio & 10.6 \\
Breathing rate & 8.23 \\
Milk transfer coefficient & 6.11 \\
Humidity & 5.80 \\
Milk consumption & 2.91 \\
Fraction of vegetation that is water & 2.70 \\
Beef transfer coefficient & 2.43 \\
Dairy cattle consumption of forage & 1.78 \\
Leafy vegetable consumption & 1.36 \\
Beef consumption & 1.36 \\
Beef cattle consumption of forage & 0.39 \\
Feed storage time & 0.065 \\
Fraction of year animals graze & 0.028 \\
Fraction of daily feed that is pasture grass & 0.0087 \\
Transport time for produce & 0.0021 \\
Transport time for milk & 0.00057 \\
Transport time for leafy vegetables & 0.00031 \\
Time from slaughter to consumption & 0
\end{tabular}

${ }^{a}$ Defined as the ratio of the maximum adult dose distribution's standard deviation to its mean, multiplied by 100 .

etation. For adults and teenagers, pathway contributions also deviate from above observations in the months of June through September. In these months, inhalation (including absorption) is the primary contributor to dose, while vegetation is the secondary contributor. Again, this deviation is the result of higher humidity values in these months.

\subsection{SENSITIVITY ANALYSIS}

The results of the performed sensitivity analysis are given in Table III. The most sensitive parameters are the inhalation and ingestion dose factors, indicating that addressing the uncertainty in these variables is of primary importance. The next most sensitive parameters are the vegetation to air concentration ratio and the breathing rate, followed by the milk transfer coefficient. The dose model is not sensitive to transport times due to the relatively long half-life of tritium (Hamby, 1993). The importance of dose conversion factors has been suggested previously (Hoffman and Baes, 1979). 


\subsection{DOSE DISTRIBUTIONS}

Consistent with previous work (Hamby, 1993), a plot of dose distributions suggests that total environmental dose is lognormally distributed. The range of the infant dose distribution is approximately a factor of 200 , and is generally higher than the range noted for the adult dose distribution, which ranged approximately a factor of 80. This result is attributable to the larger difference between infant minimum and maximum dose factor values, coupled with the large influence that the dose factor has on the distribution variance. A review of the data indicated a trend of higher adult mean dose in relation to calculated deterministic dose. This finding is the result of a large maximum adult breathing rate and a larger variation in values from the mean to maximum rate than is observed for other age groups. Therefore, adult mean values are highest over all age groups, although dose calculations indicate the adult total dose is lowest. This is especially accentuated in population dose means due to the large proportion of the population that are adults.

\section{Discussion}

This study suggests that, over a five year period, the use of averaged meteorological data results in the calculation of conservative environmental tritium doses. The magnitude of this conservatism, however, is less than $10 \%$ compared to monthly averaged dose estimates. The need for monthly dose estimations for purposes of dose reconstruction must be evaluated on site to site basis. Although it is clear that monthly estimates are more accurate, whether it is cost effective and necessary for the protection of public health to evaluate monthly doses is a subjective decision.

The distributions generated for maximum individual and population doses for each month more realistically represent the doses calculated in comparison to deterministic values. Differences noted in dose ranges between age groups as well as discrepancies in predicted versus deterministic mean values clearly emphasize the need for addressing the uncertainty in parameter values.

Although the results of this study provide a general view of discrepancies in dose estimations when averaged meteorological data is utilized, several additional uncertainties exist in the model which were not considered in this report. Some uncertainties specific to the estimation of environmental doses due to atmospheric tritium releases which were not considered are the quantities of chemical forms of tritium present in the air, uncertainties in release rates, and uncertainties in wind speeds. In performing an uncertainty analysis, it was assumed that all parameters are independent, the Gaussian model being utilized was not biased, and parameter values and their relative distributions were representative of the population surrounding the Savannah River Site (Miller et al., 1982).

Uncertainties in the estimated air concentration and source term were not investigated. It has been demonstrated that air concentration values do not contribute 
significantly to uncertainty in relation to variables such as the dose conversion factor utilized (Hoffman and Baes, 1979). However, future research efforts in this area may attempt to confirm the role of air concentration estimates in introducing error in dose estimates. Little and Miller (1979) reported that monthly and seasonal averages using the Gaussian model up to $100 \mathrm{~km}$ can be predicted within a factor of 4 .

In addition, the adequacy of models utilized at the Savannah River Site for environmental dose predictions have been scrutinized. Draxler (1980) reported that the Gaussian model consistently over-predicted seasonal and annual long term krypton- 85 predictions by a factor of four at the site due to averaging of wind speeds and assumptions of constant stability from the release point to the receptor. Furthermore, although sufficient correlation between predicted and measured air concentrations while implementing the Gaussian model at $40 \mathrm{~km}$ has been observed, the correlations at the site boundary and at $80 \mathrm{~km}$ are not as promising (Murphy et al., 1992). Murphy (1992) attributes this divergence to estimation of the vertical dispersion of the plume. This observation is supported with previous work recommending the use of data other than Pasquill-Gifford curves in estimating plume dispersion (Miller and Little, 1980). More specifically, Miller and Cotter (1988) suggested that dispersion parameters based on measurements near Julich, Federal Republic of Germany, yield the best comparisons between observed and expected air concentrations. Future investigations of site modeling procedures should investigate the possibility of utilizing various data sources in calculating dispersion coefficients.

\section{Conclusion}

In summary, this research investigated the need for examination of monthly environmental dose estimates for purposes of dose reconstruction. The sum of monthly doses based on time-specific meteorological data were compared to annual averaged doses determined from a five year meteorological database. It was found that annual-averaged data overestimates environmental dose estimates for every age group and exposure pathway, compared to monthly-averaged data, by $2 \%$ to $6 \%$. The basis of differences in monthly and annual dose estimates was observed to stem from basic misrepresentations of monthly meteorological data by the five-year database, resulting in divergent air concentration estimates. Discrepancies from expected air concentrations were represented in all pathways, although some differences in the degree of dissimilarity were noted between inhalation and absorption pathways and ingestion. The implications of these discrepancies must be evaluated on a site-to-site basis in light of site-specific public health and cost considerations.

The relative contributions of exposure pathways were evaluated. It was found that milk is the primary contributor to infant dose, while vegetation is the major contributor to total dose in other age groups. In addition, pathway contributions 
over time were investigated. Results indicate that pathway contributions to infant dose remain constant over a year, while the relative importance of inhalation and absorption of tritium through the skin for other age groups increases in importance in the months of June to September due to increased humidity values and a resulting decrease in vegetation tritium concentrations.

In examining the uncertainties associated with deterministic doses, it was found that the model utilized was most sensitive to dose factors, the ratio of the specific activity of tritium oxide in vegetation to that in the atmosphere, and breathing rates. Further, it was found that adult distribution means were higher than infant distribution means, and that the range in infant doses was larger than the range in adult dose distributions.

\section{Acknowledgement}

The authors would like to thank the Environmental Technology Section of the Savannah River Technology Center for providing Site data. This research was performed under appointment to the Applied Health Physics Fellowship Program administered by Oak Ridge Institute for Science and Education under contract number DE-AC05-76OR00033 between the U.S. Department of Energy and Oak Ridge Associated Universities.

\section{References}

Ansphaugh, L. R., Koranda, J. J., Robison, W. L. and Martin, J. R.: 1973, 'The Dose to Man via Foodchain Transfer Resulting from Exposure to Tritiated Water Vapor', in Moghissi, A. A. and Carter, M. W. (eds.), Tritium, Phoenix, AZ: Messinger Graphics, pp. 405-421.

Brodsky, A.: 1982, 'Models for Calculating Doses from Radioactive Materials Released to the Environment', in Handbook of Radiation Measurement and Protection, CRC Press. Boca Raton, FL: Vol. 2. pp. 367-422.

U.S. Department of Energy: 1988, Internal dose conversion fractors for calculation of dose to the public. Washington, DC: Report \#EH-0071.

Draxler, R.: 1980, An improved gaussian model for long-term average air concentration estimates. Atmospheric Environment 14, 597-601.

Etnier, E. and Till, J.: 1979, Significance of incorporating age-dependent data into population dose estimates. Health Physics 37, 774-777.

Hamby, D. M. and Jumper, C. E.: 1990, Average absolute humidity at the Savannah River Site. Westinghouse Savannah River Company. Aiken, SC: Report No. SRL-ETS-900141.

Hamby, D. M.: 1992, Site specific parameter values for the nuclear regulatory commission's food pathway dose model. Health Physics 62, 136-143.

Hamby, D. M.: 1993, A probabilistic estimation of atmospheric tritium dose. Health Physics $\mathbf{6 5}$, 33-40.

Hamby, D. M. and Bauer, L. R.: 1994, The vegetation-to-air concentration ratio in a specific activity atmospheric tritium model. Health Physics 66, 339-342.

Hoffman, F. O. and Baes, C. F. (eds.): 1979, A statistical analysis of selected parameters for predicting food chain transport and internal doses of radionuclides. Oak Ridge National Laboratory. Oak Ridge, TN: Report No. ORNL/ NUREG/TM-282 /NUREG-1004. 
International Commission on Radiological Protection (ICRP): 1989, Age-dependent doses to members of the public from the intake of radionuclides: Part I. Pergamon. Oxford. Publication No. 56.

International Commission on Radiological Protection (ICRP): 1993, Age-dependent doses to members of the public from the intake of radionuclides: Part II. Pergamon. Oxford. ICRP Publication No. 67.

Little, C. A. and Miller, C. W.: 1979, The uncertainty associated with selected environmental transport models. Oak Ridge National Laboratory. Oak Ridge, TN: Report No. ORNL 5528.

Miller, C. W. and Little, C. A.: 1980, Accuracy of gaussian plume dispersion model predictions as a function of three atmospheric stability classification calculations. Health Physics 39, 773-782.

Miller, C. W. and Hoffman, F. O.: 1982, Review of uncertainty estimates associated with models for assessing the impact of breeder reactor radioactivity. Oak Ridge National Laboratory. Oak Ridge, TN: Report No. ORNL 5832.

Miller, C. W., Field, D. and Cotter, S.: 1988, Examination of the uncertainty in air concentration prediction using hanford field data. Health Physics 55, 443-450.

Murphy, C. E.: 1984, The relationship between tritiated water activities in air, vegetation, and soil under steady state conditions. Health Physics 47, 635-639.

Murphy, C. E., Bauer, L. R., Hayes, D. W., Marter, W. L., Zeigler, C. C., Stephenson, D., Hoel, D. D. and Hamby, D. M.: 1993, Tritium in the savannah river site environment. Westinghouse Savannah River Company. Aiken, SC: Report No. WSRC-RP-90-424-1.

Murphy, C. E., Bauer, L. R. and Hoel, D. D.: 1992, Tritium atmospheric transport and deposition following acute releases-comparisons with a simple transport model. Fusion Technology 21, 489-493.

Okada, S. and Momoshima, N.: 1993, Overview of tritium: characteristics, sources, and problems. Health Physics 65, 595-609.

O'Kula, K. R., East, J. M. and Murphy, C. E., Jr.: 1992, Assessment of airborne release methodology for tritium from U.S. DOE facilities. Westinghouse Savannah River Company. Aiken, SC.

Simpkins, A. A. and Hamby, D. M.: 1997, Predicted versus measured tritium oxide concentrations at the Savannah River Site. Health Physics 72, 179-185.

United States Department of Agriculture: 1983, Food consumption: households in the south, seasons and year 1977-78. National food consumption survey 1977-78. Washington, DC: Report No. H-9.

U.S. Nuclear Regulatory Commission: 1977, Calculation of annual dose to man from routine releases of reactor effluents for the purpose of evaluating compliance with 10 CFR Part 50, Appendix I. Washington, D.C: Regulatory Guide 1.109, Revision 1.

U.S. Nuclear Regulatory Commission: 1978, Preparation of environmental reports for nuclear power stations. Washington, D.C.: Regulatory Guide 4.2.

Westinghouse Savannah River Company: 1991, Savannah River Site environmental report, 1990. Aiken, SC: Report No. WSRC-IM-91-28.

Westinghouse Savannah River Company: 1994, Savannah River Site environmental data for 1993. Aiken, SC: Report No. WSRC-TR-94-077.

Westinghouse Savannah River Company: 1995, Savannah River Site environmental data for 1994. Aiken, SC: Report No. WSRC-TR-95-077. 